Review

\title{
Recent Status of Fishes in the Yangtze River and its Ecological Health Assessment
}

\author{
1,2, $†$ Chun-Jiao Lu, ${ }^{2}, \dagger$ Jin-Jing Duan, ${ }^{1}$ Muhammad Junaid, \\ ${ }^{2}$ Tuan-Wu Cao, ${ }^{2}$ Shi-Min Ding and ${ }^{1}$ De-Sheng Pei \\ ${ }^{I}$ Chongqing Institute of Green and Intelligent Technology, Chinese Academy of Sciences, Chongqing 400714, China \\ ${ }^{2}$ Yangtze Normal University, Chongqing 408100, China
}

\section{Article history}

Received: 02-12-2015

Revised: 01-03-2016

Accepted: 25-03-2016

Corresoonding Author:

Shi-Min Ding

Yangtze Normal University,

Chong Qing 408100, China

and De-Sheng Pei

Chongqing Institute of Green and Intelligent Technology,

Chinese Academy of Sciences, Chong Qing 400714, China

Email: dingshimin@yznu.edu.cn and peids@cigit.ac.cn

$\dagger$ These authors contributed equally to the manuscript.

\begin{abstract}
The Yangtze River, ranking behind the Nile and the Amazon rivers, is the third longest river in the world. The Three Gorges Dam constructed on the Yangtze River dramatically altered the ecological environment in the surroundings. In this review, we integrated the published data about the Three Gorges Project and systematically analyzed the status of fish population in the Three Gorges Reservoir for recent fifteen years (2000 2014). Meanwhile, Fish Index of Biotic Integrity (F-IBI) system was used to assess the health risks to the ecological environment in the Three Gorges Reservoir Basin. This review indicated that the yields of natural fish catch decreased in the Yangtze River Basin (Dongting Lake, Poyang Lake, the downstream of the Three Gorges Dam and the Three Gorges Reservoir) during the recent fifteen years (2000 2014). The overall trends of natural fishing catch for Dongting Lake, Poyang Lake and the Three Gorges Reservoir went down. The fry runoff volume of four major Chinese carps in Jianli section decreased by about $80 \%$ from 2002 to 2003 . In addition, the construction of the Three Gorges Dam left significant impacts on the populations of endemic fish and rare fish on the upper reaches of the Yangtze River. The F-IBI scores for the upstream Yangtze River gradually went down after 2003, but still maintained in general level. Our findings about the status of fish population and the ecological risk assessment of the Yangtze River, which will be helpful for Chinese government in decision making for the sustainable development of the Three Gorges Reservoir Area and comprehensive ecosystem management in the Yangtze River Basin.
\end{abstract}

Keywords: Three Gorges Project, Three Gorges Reservoir Region, The Yangtze River, F-IBI, Ecological Health

\section{Introduction}

In China, the Three Gorges Dam, located in Yichang, Hubei province, is a hydroelectric dam that spans the Yangtze River. The Yangtze River Basin has numerous tributaries, rich in fish resources with wide basin areas (Xu et al., 2012; Sun et al., 2012; Guo et al., 2012; Liu et al., 2013; Bao et al., 2015; Xu et al., 2015; Ye et al., 2014) (Fig. 1). The Three Gorges Project was started in December 1994, begun to generate power in 2003 and 2nd Phase construction was completed in 2009. Before the Three Gorges Project was launched, the Yangtze River was the habitat of 370 species of fish (294 species for pure freshwater fish, 22 species for salty freshwater fish, 9 species for sea freshwater migratory fish and 45 species for marine fish) (Chen, 2003). Although the Three Gorges Project has made great achievements in flood control, power generation, navigation and water resource management (Zhao and Liu, 2015; Ran et al., 2011), but it has entirely changed the status of the Yangtze River Basin's hydrology and disturbed the balance of the intact ecosystem. Thus, the Chinese government pays close attention to the ecological restoration of the Three Gorges Reservoir, including fish population and ecological health problems. 


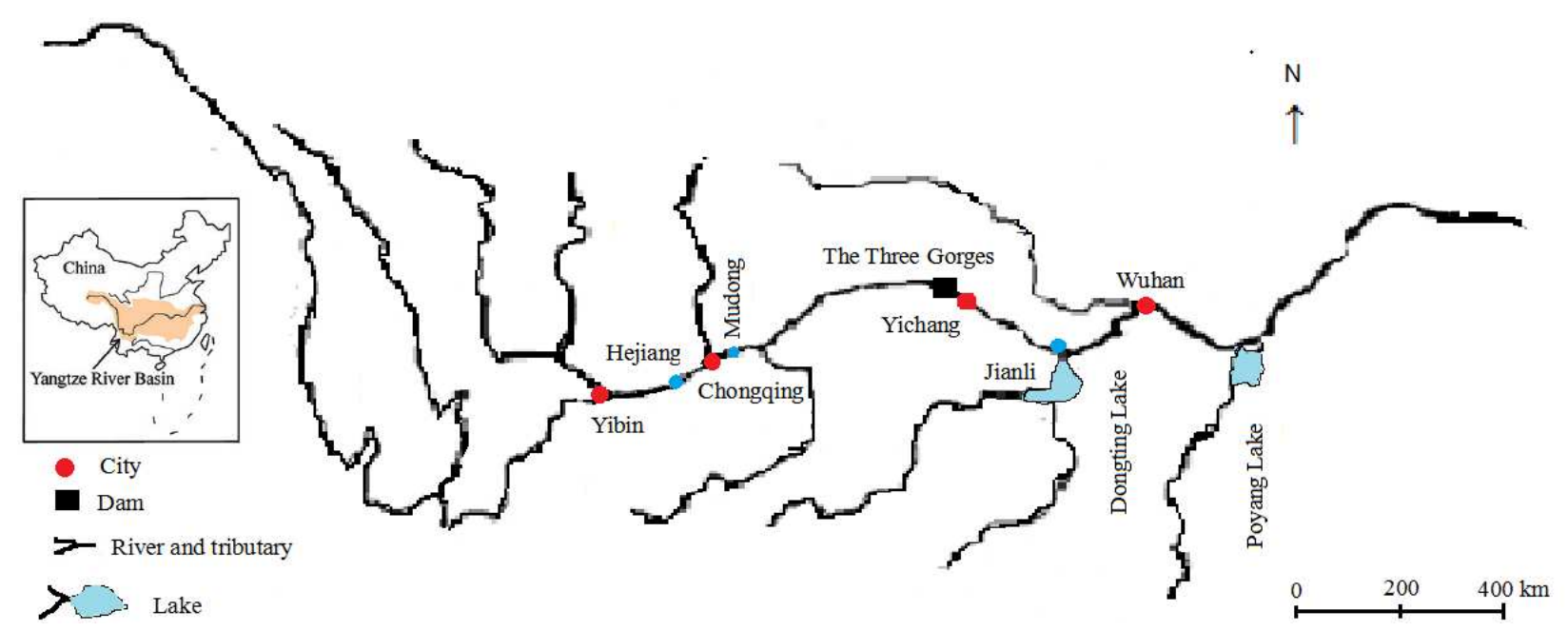

Fig. 1. The diagram of the Yangtze River Basin

In 2003, the construction of the Three Gorges Project Phase II was revamped for its water storage capacity, navigation system and power generation. Therefore, this construction time period is of critical importance for ecologists to analyze the data of fish yields in the Yangtze River from year 2000 to 2014. In this review, the fry runoff volume of native fish was scrutinized in the upstream Yangtze River, the Three Gorges Reservoir and the downstream of the Three Gorges Dam, Dongting Lake and Poyang Lake, respectively. We have also systematically analyzed the trends of natural fishing yield, commercial fish stocks, endemic fish and rare fish resources of the Three Gorges Reservoir for recent fifteen years (2000-2014). After survey and data analysis, Fish Index of Biotic Integrity (F-IBI) system was applied to assess the ecological risk of the Three Gorges Project to aquatic life in the Yangtze River. Comprehensive analysis of the impacts on fish in Yangtze River caused by Three Gorges Project will be helpful for the government and relevant departments to formulate environmental protection strategies. The yearly variations of ecological health will provide guidelines on how to use the Three Gorges Reservoir Area as resource for sustainable development in China and also set up a typical example for other sustainable hydraulic engineering in the world.

\section{Status of Fish Resources in Yangtze River Basin}

\section{The Yields of Natural Fishing}

The fishery resources data were excavated from the Bulletin on the Ecological and Environmental Monitoring Results of the Three Gorges Project from 2000 to 2014 (SEPA, 2001; 2002; 2003; 2004; 2005;
2006; 2007; 2008; 2009; 2010; 2011; 2012; 2013; 2014; 2015 ) to elucidate the yields of natural fish for the Three Gorges Reservoir, the downstream of the Three Gorges Dam, Dongting Lake and Poyang Lake. The natural fishing yield for Dongting Lake, Poyang Lake and the downstream of Three Gorges Reservoir showed a definite declining trend. The natural fishing yield for the Three Gorges Reservoir went down from 2000 to 2005, but the yields began to show an upward trend after 2005 (Fig. 2). The reason might have close relationship with fish artificial propagation and releasing or improved water quality after 2005. Interestingly, the rebounds of the natural fishing yield in Dongting Lake and Poyang Lake contributed to the increase point for the total natural fishing yields in 2010. Although the total natural fishing yields had some instability, the overall trend was still decreased (Fig. 2).

\section{The Trends of Commercial Fish Resources}

Four major Chinese carps (Mylopharyngodon piceus, Ctenopharyngodon idellus, Hypophthalmichthys molitrix and Aristichthys mobilis) are pivotal commercial fish in China (FRSCYRWS, 1990). The Yangtze River has the best breeding habitats for the four major Chinese carps. In 1960s, the spawning size of four major Chinese carps in Yangtze River was reached 115 billion (Yu, 1985). However, since the 1970s, the fish stocks in the Yangtze River have been declining. In 1980s, the spawning size of four major Chinese carps reached 17.35 billion in the middle of Yangtze River (SEPA, 2004). According to the published data (SEPA, 2001; 2002; 2003; 2004), the fry runoff volume of four major Chinese carps in Jianli (the middle reaches of the Yangtze River) was 2.854 billion. The year 2003 was the end point for the second phase of the Three Gorges Project and three goals: (1) 
Impoundment, (2) shipping, (3) power generation were preliminarily achieved. However, the spawning of four major Chinese carps was adversely affected in consequence. As shown in Fig. 3, the fry runoff of four economic carps in Jianli section dramatically declined in 2003. In 2009, the fry runoff of the four major Chinese carps in Jianli section reached the decade's lowest yield (SEPA, 2010) (Fig. 3).

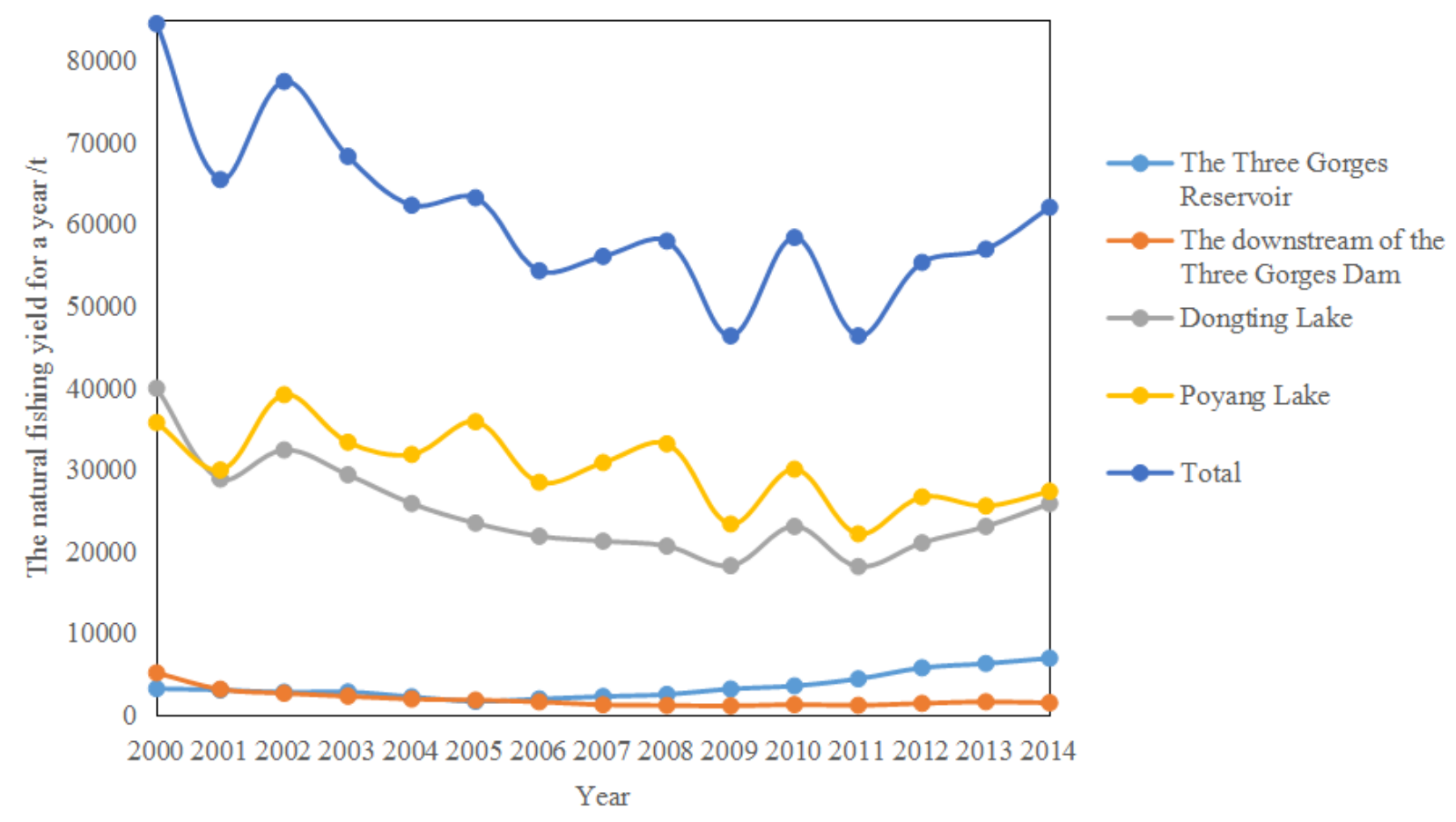

Fig. 2. Trend curve of natural fishing yield for the Yangtze River Basin from 2000 to 2014

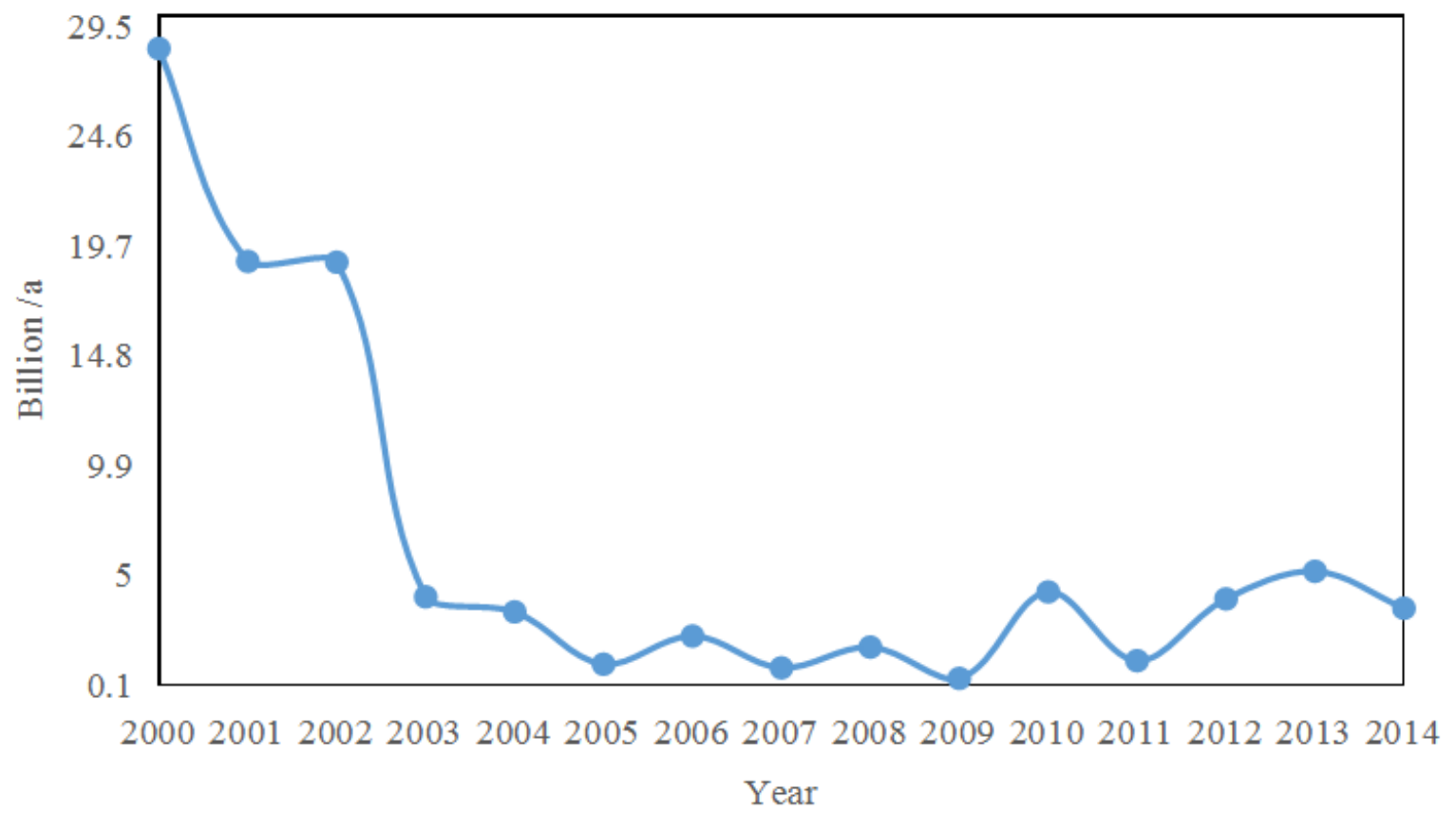

Fig. 3. The trend curve of fry runoff for four major Chinese carps in Jianli from 2000 to 2014 


\section{The Trends of Endemic Fishes in the Upper Yangtze River}

The source of the Yangtze is located in the Tanggula Mountains on the border of Qinghai Province and Tibet Autonomous Region. The upper reaches of the Yangtze River is an important breeding grounds for freshwater fish species. There are about 189 species of fish in the upper reaches of Yangtze River, of which more than 40 species are endemic before 1976 (STSGDFCR, 1982; Gao et al., 2013). The data analysis of the last 13 years portrayed significant variations for the endemic fish population in the upstream of the Yangtze River (Fig. 4). The upper reaches of the Yangtze River showed relatively stable trends, in the Yinbin (Yibin is located in the Yangtze River upstream) and Hejiang (Hejiang is located in the downstream of Yibin, but still belongs to the upstream of the Yangtze River) and the endemic fish populations were not greatly affected. However, the endemic fish species in the reservoir area was decreased and the Wanzhou (Wanzhou is in the downstream of the Hejiang), Zigui (Zigui is located in the downstream of the Three Gorges Dam) and the Yichang city (Zigui county belongs to Yichang city) also exhibited the decreasing trends for the endemic fish. Therefore, the construction of the Three Gorges Project had significant impacts on endemic fish population on the upper reaches of the Yangtze River (SEPA, 2001; 2002; 2003; 2004; 2005; 2006; 2007; 2008; 2009; 2010; 2011; 2012; 2013; 2014; 2015).

\section{The Changes of Rare Fishes in the Yangtze River}

Most of rare fishes in the Yangtze River have been greatly threatened, due to construction of dams, wastewater pollution and ship transportation, such as Chinese sturgeon (Acipenser sinensis), Dabry's sturgeon (Acipenser dabryanus), Chinese paddlefish (Psephurus gladius) and Mullet (Myxocyprinus asiaticus) etc.

The number of Chinese sturgeon in the upper reaches of the Yangtze River was 450 in year 2000, which population reached almost half, compared to the population level of 1995 . Therefore, the survival of Chinese sturgeon is facing serious threat in Yangtze River. Data from the Bulletin on the Ecological and Environmental Monitoring Results of the Three Gorges Project proved that the Chinese sturgeon had twice spawning activity on October 27 and November 9 , in 2002. But the average of the annual spawning was significantly decreased, compared to 1998 and 1999. From 2004 to 2011, the spawning activity of Chinese sturgeon was noticed only once and the spawning increased by twice in 2012. By using the sonar technique, the number of Chinese sturgeon detected was quite low. The impounding period of the Three Gorges Reservoir was overlapped by the spawning activity of Chinese sturgeon. It indicated that the reduction of discharge caused by the impoundment of the reservoir resulted in the decline of spawning scale of Chinese sturgeon (Chen, 2007; Wu et al., 2004; Fu et al., 2003).

Currently, the fish catches of the Chinese paddlefish and the Dabry's sturgeon were almost zero in the upper reaches of the Yangtze River according to catch record. However, the Dabry's sturgeon used to be one of the leading commercial fishes in the Yangtze River before the mid-seventies. When the Three Gorges Project was initiated, the population size of rare fish is on the decline (SEPA, 2001; 2002; 2003; 2004; 2005; 2006; 2007; 2008; 2009; 2010; 2011; 2012; 2013; 2014; 2015). After 1995, the number of Dabry's sturgeon began to decrease sharply. In 2001, there was no Dabry's sturgeon in the Luzhou section of the Yangtze River Basin (Zhu et al., 2009). Fortunately, the number of mullet was relatively more in the conservation area. The upper reaches of the Yangtze River is no longer the mullet fingerlings concentrated area.

\section{The Change of the Fish Biological Integrity in Yangtze River}

Biological integrity can be used to measure the changes in the composition of biologic communities to reflect the ecological complexity (Broecka et al., 2015; Lavoiea et al., 2014; Lee and An, 2014; Ondiviela et al., 2015; Wang et al., 2015). Ecosystem health assessment can be divided into two categories: Qualitative evaluation, quantitative evaluation. Index of Biotic Integrity (IBI) is a quantitative method to evaluate ecosystem health. In 1981, Karr developed a method to evaluate water quality by using biome species composition, trophic structure and individual health status indicators. He presented 12 indicators of the environmental health (Karr, 1981; Karr and Dudley, 1981; Faush et al., 1990). Integration of the complexity of the ecosystem and biological integrity can conduct a comprehensive analysis of the ecosystem health. Thus, IBI index system became a standard assay and developed to fish F-IBI, benthic fauna B-IBI and plankton P-IBI (Zhu and Chan, 2004; Uzarski et al., 2005. The Yangtze River Basin is rich in fish resource, therefore F-IBI will help to calculate and evaluate the biological integrity and ecological health rating of the Yangtze River (Zhu and Yang, 2013; Cui and Wan, 2006; Chen and Zhou, 2001; Qiao and Guo, 2012; Liu et al., 2007). Adapted F-IBI System and the score of biological integrity are shown in Table 1 and 2. 


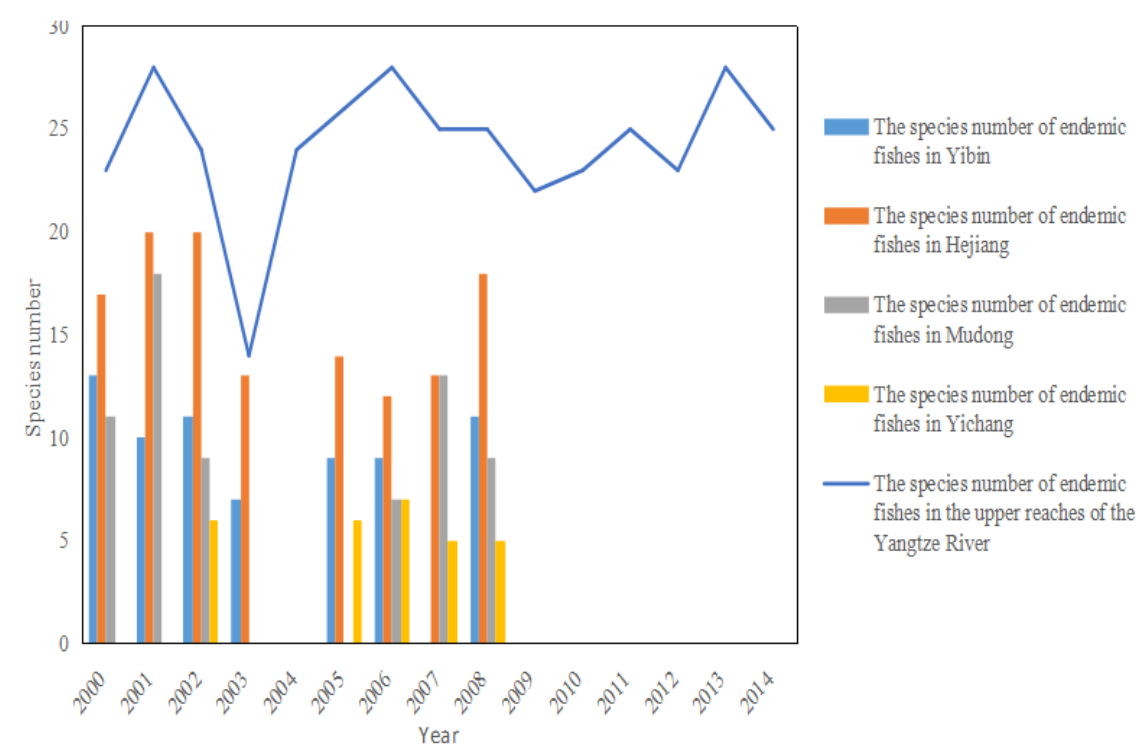

Fig. 4. The trend histogram of endemic fishes taxa in the upper reaches of the Yangtze River from 2000 to 2014

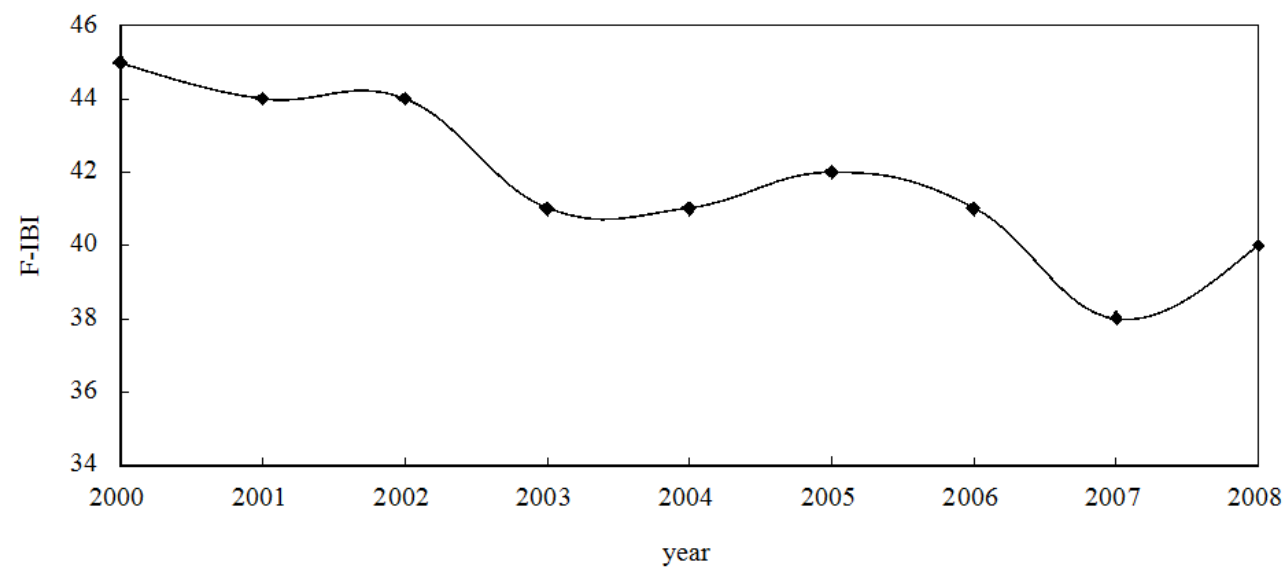

Fig. 5. The trend of F-IBI value for the upper reaches of the Yangtze River (Yibin to Yichang section) from 2000 to 2008

Table 1. Adapted F-IBI system for the upper reaches of the Yangtze River*

\begin{tabular}{|c|c|c|c|c|c|}
\hline \multirow[b]{2}{*}{ Attributes } & \multirow[b]{2}{*}{ Number } & \multirow[b]{2}{*}{ Indices } & \multicolumn{3}{|c|}{ Scoring standards } \\
\hline & & & 5 & 3 & 1 \\
\hline \multirow[t]{6}{*}{ Category structure } & 1 & Total fish species & $>50$ & $30 \sim 50$ & $<30$ \\
\hline & 2 & Percent of cyprinid species & $<55$ & $55 \sim 70$ & $>70$ \\
\hline & 3 & Percent of cobitidae species & $0 \sim 5$ & $5 \sim 8$ & $8 \sim 12$ \\
\hline & 4 & Percent of bagridae species & $5 \sim 15$ & $15 \sim 20$ & $>20$ \\
\hline & 5 & Percent of tolerance individuals & $<5$ & $5 \sim 10$ & $>20$ \\
\hline & 6 & Species richness of fishing & $>20$ & $10 \sim 20$ & $<10$ \\
\hline \multirow[t]{3}{*}{ Trophic structure } & 7 & Proportion of omnivorous species & $<55$ & $55 \sim 70$ & $>70$ \\
\hline & 8 & Proportion of benthic fishes & $>40$ & $20 \sim 40$ & $<20$ \\
\hline & 9 & Proportion of piscivorous species & $>15$ & $5 \sim 15$ & $<5$ \\
\hline \multirow[t]{3}{*}{ Richness and health } & 10 & Yield per unit of fishery & $>2$ & $1 \sim 2$ & $<1$ \\
\hline & 11 & Proportion of invasive species & $<1$ & $1 \sim 2$ & $>2$ \\
\hline & 12 & Proportion of infectious disease and abnormal shape individuals & $<2$ & $2 \sim 5$ & $>5$ \\
\hline
\end{tabular}

*The Calculation method of F-IBI: Scores were calculated in terms of different attributes according to scoring standards, then the summation was made 
Table 2. The classification of biological integrity based on FIBI scores

\begin{tabular}{ll}
\hline F-IBI score & Biological integrity \\
\hline $58 \sim 60$ & Excellent \\
$48 \sim 52$ & Good \\
$40 \sim 44$ & Fair \\
$28 \sim 34$ & Poor \\
$12 \sim 22$ & Very poor \\
NF & No fish \\
\hline
\end{tabular}

According to F-IBI values for the Yangtze River Basin provided by Zhu and Chan (2004; Uzarski et al., 2005; Zhu and Yang, 2013; Cui and Wan, 2006; Chen and Zhou, 2001; Qiao and Guo, 2012; Liu et al., 2007), we integrated their data and deduced the ecological health status of the upper basin of the Yangtze River from 2000 to 2008 (Fig. 5). The score of F-IBI indicated that the ecological health of the Yangtze River was good in 2000. After 2000, the value of F-IBI was gradually decreased to the general level. There were two troughs in 2003 and 2007. Since the water level of dam was reached 135 meters for the first time in June 2003, this could be the one of the reasons for the less scores of F-IBI in 2003. After 2003, the Three Gorges Dam began to store water, resulted in fluctuations in water level. In consequence, the changes in the spanning activity was also observed. F-IBI is based on indicators of biological integrity of fish, therefore such changes deeply affect F-IBI. As the Phase II construction was started in 2003, it can be seen that the ecological health of the Yangtze River illustrated a downward trend in 2003 and 2007, but the major biological integrities were at a general level. In 2007, the average temperature in the Three Gorges Reservoir was high and the annual rainfall was above normal. These could be some of the reasons that influenced fish spawning and ultimately reduced F-IBI scores of the Yangtze River (SEPA, 2008).

\section{Conclusion and Recommendation}

According to the reviewed data in this study, we found that natural fish catch in the Yangtze River was reduced in last fifteen years. The fry runoff volume for four major Chinese carps dramatically decline from 2000 to 2009 and rebounded in 2010, but the number of commercial fish in the upper reaches of the Yangtze River is far worse than before. The rare and endemic fish species of the upper reaches of the Yangtze River, such as Chinese sturgeon, Dabry's sturgeon, Chinese paddlefish and Mullet also dropped. During the period 2000 to 2008, the declining trends of F-IBI values of the upstream Yangtze River was distinct.

Although the Three Gorges project greatly improved flood control, power generation and shipping, but it has largely influenced the ecological environment. With the completion of the Three Gorges Project, some of the major ecological concerns have generated. Moreover, overfishing, agricultural non-point source pollution (NPS), industrial wastewater and municipal sewage are also major factors for fish resources decline in the Yangtze River Basin. In order to attain sustainable development status in the Three Gorges Reservoir Area, fish catch should be reduced. Fish artificial propagation and release may be reasonably improve the ecological health and fish diversity in the Yangtze River. Fortunately, Chinese government pays more attention to solve the ecological and environmental problems in the Yangtze River, especially in the Three Gorges Reservoir Area.

Finally, fish analysis can't fully assesses in-depth and detailed impacts of the Three Gorges Project on the Yangtze River Basin. To determine the effect of the Three Gorges Project on the Yangtze River fish and its basin's ecological health, researchers must need long-term scientific and cutting edge investigations to draw an experimental based empirical conclusion. This review indicates that the Three Gorges Project may have an impact on the Yangtze River fish and disturbed the ecological integrity of the Yangtze River Basin. Albeit, the specific aspects and the analysis of the pros and cons need more comprehensive research.

\section{Acknowledgement}

The authors are grateful for supports from the Hundred Talents Program of Chinese Academy of Sciences, the Key Application and Development Program of Chongqing Science and Technology Commission (Grant No. cstc2014yykfC20004 and cstc2014yykfC20002), the Science and Technology Project of Chongqing Municipal Education Commission (KJ1401202), the Science and Technology Project of Fuling District, Chongqing (FLKJ2013ABB2098), the Application and Development Program of Science and Technology Commission of Beibei District, Chongqing (2015-07), the Scientific Research Starting Foundation for Returned Overseas Chinese Scholars from Ministry of Education and the National Technology Foundation for Selected Overseas Chinese Scholar of Chongqing Human Resources and Social Security Bureau, China.

\section{Author's Contributions}

Chun-Jiao Lu and Jin-Jing Duan: Contributed equally to the manuscript.

Muhammad Junaid and Tuan-Wu Cao: Revised the paper. 
Shi-Min Ding: Conceived and designed this review.

De-Sheng Pei: Conceived and designed this review, wrote the paper and revised the paper.

\section{Conflict of Interest}

The authors declare no conflict of interest.

\section{References}

Bao, Y., P. Gao and X. He, 2015. The water-level fluctuation zone of three gorges reservoir-a unique geomorphological unit. Earth-Sci. Rev., 150: 14-24. DOI: 10.1016/j.earscirev.2015.07.005

Broecka, M., A. Waterkeyna, L. Rhazic, P. Grillasb and L. Brendoncka, 2015. Assessing the ecological integrity of endorheic wetlands, with focus on Mediterranean temporary ponds. Ecol. Indicat., 54: 1-11. DOI: 10.1016/j.ecolind.2015.02.016

Chen, D., 2003. The conservation strategy of Yangtze River fishery. China Fisheries, 17-19

Chen, X. and Y. Zhou, 2001. Sustainable development of fishery resources. Resources Sci.

Chen, Y.B., 2007. Studies on the influences of the operation of The Three Gorges Dam on reproduction of the Chinese sturgeon, Acipenser sinensis: The ecohydrological mechanism and conservation strategy. Institute of Hydrobiology, Chinese Academy of Sciences.

Cui, H. and L. Wan, 2006. A brief discussion on the legal protection of fishery resources along the Yangtze River. Resources Environ. Yangtze River, 1: 58-60.

Faush, K., J. Lyon, J. Karr and P. Angermeier, 1990. Fish communities as indicators of environmental degradation. Am. Fisheries Society Symp., 8: 123-144.

FRSCYRWS, 1990. Fishery Resources Survey Consortium of the Yangtze River Water System. 1st Edn., Ocean Press, Beijing, pp: 250.

$\mathrm{Fu}, \mathrm{C}$, J. Wu, J. Chen, Q. Wu and G. Lei, 2003. Freshwater fish biodiversity in the Yangtze River basin of China: Patterns, threats and conservation. Biodiversity Conserv., 12: 1649-1685. DOI: $10.1023 / \mathrm{A}: 1023697714517$

Gao, T., H. Tian, C. Ye and X. Duan, 2013. Diversity and composition of fish in the mainstream of national nature reserve of rare and endemic fish in the upper Yangtze River. Freshwater Fisheries, 2: 36-41.

Guo, H., Q. Hu, Q. Zhang and S. Feng, 2012. Effects of the three gorges dam on Yangtze River flow and river interaction with Poyang Lake, China: 2003-2008. J. Hydrol., 416-417: 19-27. DOI: 10.1016/j.jhydrol.2011.11.027

Karr, J. and D. Dudley, 1981. Ecological perspective on water quality goals. Environ. Manage., 5: 55-68. DOI: 10.1007/BF01866609
Karr, J.R., 1981. Assessment of biotic integrity using fish communities. J. Fisheries, 6: 21-27.

DOI:

$10.1577 / 1548$

8446(1981)006<0021:AOBIUF>2.0.CO; 2

Lavoiea, I., S. Campeaub, N. Zugic-Drakulicc, J. Winterd and C. Fortina, 2014. Using diatoms to monitor stream biological integrity in Eastern Canada: An overview of 10 years of index development and ongoing challenges. Sci. Total Environ., 475: 187-200. DOI: $10.1016 /$ j.scitotenv.2013.04.092

Lee, J. and K. An, 2014. Integrative restoration assessment of an urban stream using multiple modeling approaches with physical, chemical and biological integrity indicators. Ecol. Eng., 62: 153-167. DOI: 10.1016/j.ecoleng.2013.10.006

Liu, J., C. Zang, S. Tian, J. Liu and H. Yang et al., 2013. Water conservancy projects in China: Achievements, challenges and way forward. Global Environ. Change, 23: 633-643. DOI: 10.1016/j.gloenvcha.2013.02.002

Liu, J., Q. Wei, X. Chen, D. Yang and H. Du et al., 2007. Reproductive biology and artificial Propagation of Acipenser sinensis below Gezhouba Dam. Chinese J. Applied Ecol., 6: 1397-1401. PMID: 17763749

Ondiviela, B., M. Recio1 and J. Juanes, 2015. A management approach for the ecological integrity of NE Atlantic estuaries. Ecol. Indicat., 52: 105-115. DOI: $10.1016 /$ j.ecolind.2014.12.003

Qiao, Y. and Y. Guo, 2012. Ecological protection and restoration in Changjiang River Basin: Controlled stocking programmes. Express Water Resources Hydropower Inform., 1: 48-52.

Ran, J.J., M. Chen and Y.B. Chen, 2011. Analysis on flow adjustment functions of the Three Gorges Project which affect the downstream aquatic ecosystem and environment. J. Hydroecol., 1: 1-6.

SEPA, 2001. Bulletin on the ecological and environmental monitoring results of the Three Gorges Project. State Environmental Protection Administration, China National Environmental Monitoring, Beijing.

SEPA, 2002. Bulletin on the ecological and environmental monitoring results of the Three Gorges Project. State Environmental Protection Administration, China National Environmental Monitoring, Beijing.

SEPA, 2003. Bulletin on the ecological and environmental monitoring results of the Three Gorges Project. State Environmental Protection Administration, China National Environmental Monitoring, Beijing.

SEPA, 2004. Bulletin on the ecological and environmental monitoring results of the Three Gorges Project. State Environmental Protection Administration, China National Environmental Monitoring, Beijing.

SEPA, 2005. Bulletin on the ecological and environmental monitoring results of the Three Gorges Project. State Environmental Protection Administration, China National Environmental Monitoring, Beijing. 
SEPA, 2006. Bulletin on the ecological and environmental monitoring results of the Three Gorges Project. State Environmental Protection Administration, China National Environmental Monitoring, Beijing.

SEPA, 2007. Bulletin on the ecological and environmental monitoring results of the Three Gorges Project. State Environmental Protection Administration, China National Environmental Monitoring, Beijing.

SEPA, 2008. Bulletin on the ecological and environmental monitoring results of the Three Gorges Project. State Environmental Protection Administration, China National Environmental Monitoring, Beijing.

SEPA, 2009. Bulletin on the ecological and environmental monitoring results of the Three Gorges Project. State Environmental Protection Administration, China National Environmental Monitoring, Beijing.

SEPA, 2010. Bulletin on the ecological and environmental monitoring results of the Three Gorges Project. State Environmental Protection Administration, China National Environmental Monitoring, Beijing.

SEPA, 2011. Bulletin on the ecological and environmental monitoring results of the Three Gorges Project. State Environmental Protection Administration, China National Environmental Monitoring, Beijing.

SEPA, 2012. Bulletin on the ecological and environmental monitoring results of the Three Gorges Project. State Environmental Protection Administration, China National Environmental Monitoring, Beijing.

SEPA, 2013. Bulletin on the ecological and environmental monitoring results of the Three Gorges Project. State Environmental Protection Administration, China National Environmental Monitoring, Beijing.

SEPA, 2014. Bulletin on the ecological and environmental monitoring results of the Three Gorges Project. State Environmental Protection Administration, China National Environmental Monitoring, Beijing.

SEPA, 2015. Bulletin on the ecological and environmental monitoring results of the Three Gorges Project. State Environmental Protection Administration, China National Environmental Monitoring, Beijing.

STSGDFCR, 1982. A Survey on the spawning grounds of the "Four Famous Chinese carps" in the Changjiang River after dammed by the key water control project at Gezhouba. J. Fisheries China.

Sun, Z., Q. Huang, C. Opp, T. Hennig and U. Marold, 2012. Impacts and implications of major changes caused by the three gorges dam in the middle reaches of the Yangtze River, China. Water Resources Manage., 26: 3367-3378. DOI: 10.1007/s11269-012-0076-3

Uzarski, D., T. Burton, M. Cooper, J. Ingram and S. Timmermans, 2005. Fish habitat use within and across wetland classes in coastal wetlands of the five Great Lakes: Development of a fish-based index of biotic integrity. J. Great Lakes Res., 31: 171-187. DOI: $10.1016 / \mathrm{S} 0380-1330(05) 70297-5$
Wang, X., B. Zheng, L. Liu and L. Wang, 2015. Development and evaluation of the Lake Multibiotic Integrity Index for Dongting Lake, China. J. Limnol., 74: 594-605.

DOI: $10.4081 /$ jlimnol.2015.1186

Wu, J., J. Huang, X. Han, X. Gao and F. He et al., 2004. The three gorges dam: An ecological perspective. Frontiers Ecol. Environ., 2: 241-248. DOI: $10.1890 / 1540-$ 9295(2004)002[0241:TTGDAE] 2.0.CO;2

$\mathrm{Xu}$, W., Y. Qiao and Y. Gong, 2012. Changes of fish resources in upper Yangtze River and its protection. Yangtze River, 43: 67-71.

$\mathrm{Xu}$, W., Y. Qiao, X. Chen, Y. Cai and Z. Yang et al., 2015. Spawning activity of the four major Chinese carps in the middle mainstream of the Yangtze River, during the Three Gorges Reservoir operation period, China. J. Applied Ichthyol., 31: 846-854. DOI: $10.1111 /$ jai.12771

Ye, S., Z. Li, T. Zhang, J. Liu and S. Xie, 2014. Assessing fish distribution and threats to fish biodiversity in the Yangtze River Basin, China. Ichthyol. Res., 61: 183-188. DOI: $10.1007 / \mathrm{s} 10228-013-0376-5$

Yu, Z., 1985. The Spawning Grounds of the Four Famous Chinese Carps. In: The Yangtze River after Dammed by the Water Control Project at Gezhouba, Science Press, Beijing, pp: 287-303.

Zhao, D. and J. Liu, 2015. A new approach to assessing the water footprint of hydroelectric power based on allocation of water footprints among reservoir ecosystem services. Phys. Chem. Earth, Parts A/B/C, 79-82: 40-46. DOI: $10.1016 /$ j.pce.2015.03.005

Zhu, B., H. Zhen, Y. Qiao and J. Chang, 2009. Fish stocking program in the Yangtze River. Chinese Fisheries Econom., 2: 74-87.

Zhu, D. and J. Chan, 2004. Evaluation on temporal and spatial changes of biological integrity for shallow lakes in the middle reach of the Yangtze River. Acta Ecol. Sinica, 12: 2761-2766.

Zhu, D. and Z. Yang, 2013. Application of fish index of biotic integrity in river health management. Yangtze River, 8: 65-68. 